\title{
Teachers' Involvement in Designing MERLO Items: Boundary Crossing
}

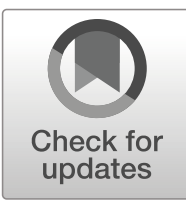

\author{
Ornella Robutti ${ }^{1} \cdot$ Theodosia Prodromou $^{2} \cdot$ Gilles Aldon $^{3}$
}

Accepted: 2 September 2020/ Published online: 12 September 2020

(C) The Author(s) 2020

\begin{abstract}
Meaning Equivalence Reusable Learning Objects (MERLO) items are a new kind of didactical tool that can be designed by teachers and used in classes, in tasks aimed at engaging students in deep reasoning, exploring and arguing about mathematical concepts. The interactions across communities of mathematics teachers and educators in on-line professional development were studied with attention to the phenomenon of boundary crossing of MERLO items, viewed as boundary objects in this article. The study analyseda first (international) crossing of the object that passedinstitutional boundaries (between Australian and Italian school systems), and a second crossing of the same object -inside the Australian institutional community - that passed boundaries (from static to dynamic representations) that we interpret in terms of method both for teachers and for researchers. This passage is possible due to the use of dynamic geometry software (GeoGebra) that supported a modification in the design of the item. The analysis shows boundary crossing as a process of transformation that can influence a modification (more or less stable) in the practices of the teachers involved and provides a deep research insight in relation to existing theoretical frameworks.
\end{abstract}

Keywords Teacher professional development · MERLO item · Boundary crossing - Boundary object $\cdot$ Communities of teachers $\cdot$ Transformation $\cdot$ Dynamic geometry software

Ornella Robutti

ornella.robutti@unito.it

Theodosia Prodromou

theodosia.prodromou@une.edu.au

Gilles Aldon

gilles.aldon@ens-lyon.fr

1 Department of Mathematics, University of Turin, Turin, Italy

2 University of New England, Armidale, Australia

3 University of Lyon, Lyon, France 
The learning of mathematical concepts takes effort over many years, in order to build "connections between different topics, to understand the coherence of mathematical ideas, and to be able to transfer learning to practical contexts and new topics" (Sullivan and Davidson 2014, pp. 605-606). It is fundamental, for coherent mathematical learning, to build connections among different representational modalities (natural language, mathematical formulae, diagrams/graphical representations, numerical representations) of a single concept (e.g. between a parabola expressed as a formula and its representation as a graph), as required in national and international assessment tests (e.g. PISA, TIMSS), in order to capture its meaning.

A wide analysis of mathematical concepts undertaken by Kilpatrick et al. (2005) recommended that, in order to speak of meaning, it is useful to take the 'spheres of practice' in which mathematical concepts are used into account, namely the rules, routines, priorities, values and actions related to the concept. Also, a sphere of practice is characterised by rules and means that refer to the communication between the 'members' of a community, and their object-related tasks (p. 10). For example, the mathematical notion of decimal numbers can assume different meanings according to different spheres of practice, such as that of shopkeepers when dealing with money or of physicians when engaged with measurements. In this article, we refer to meanings of mathematical concepts (in geometry) in school contexts and treat them within a semiotic framework, in which mathematical objects are seen as cultural products accessible by means of different registers of representation (e.g. Arzarello 2006; Duval 2006) that are easily available through the use of Dynamic Geometry Software (DGS).

In the semiotic approach, it is well recognized that the coordination of multiple representations of a particular mathematical object in different semiotic registers is fundamental for understanding (Arzarello 2006), including the process of moving from one representation to another, in a different register ('conversion', according to Duval) or within the same register ('treatment', according Duval). This ability to recognize these transformations is at the basis of meaning recognition in different representations (both in the same register and in different registers), as well as the ability to recognize two different objects in two similar representations in the same register (Fischbein 1987). Literature shows the importance of DGS in the development of theses abilities (e.g. Mariotti 2013; Sinclair and Yerushalmy 2016).

As specified by Etkind et al. (2010, 2016), Meaning Equivalence Reusable Learning Objects (MERLO) items are a suitable didactical tool to be used for supporting students recognizing the same concept across different representations (images, words, diagrams, equations, numbers, tables, etc.), because its meaning is understood, excluding representations that refer to different concepts. To solve a MERLO task (comprised of recognition, but also of explanation of the choices), students have to understand deeply the concepts represented in different registers. These tasks have been developed in a joint project in Italy and Australia for teachers' professional development. In this article, we present data from Australian in-service mathematics teachers who designed MERLO items for student to undertakerelated to mathematical concepts in the national curriculum.

The features of MERLO items are:

1) questions of varied complexity based on an understanding of mathematical meanings and the justifying of learners' reasoning; 
2) different registers of representations;

3) a focus on mathematical meanings, rather than on calculations and procedures.

We present more fully below the theoretical framework underlying the pedagogy of the use of these items.

In this article, we present an analysis of the waysin which teachers and researchers collaborated to integrate MERLO items into the formers' practices. As a consequence, we consider such items as a boundary object (Star 2010; Star and Griesemer 1989): "Boundary objects are a sort of arrangement that allow different groups to work together without consensus" (Star 2010, p. 602). Starting with a common working object, a boundary object becomes a place where different communities encounter and highlight multiple interpretations that can then evolve a mutual understanding of the object.

Leaning on the ideas of boundary crossing (Akkerman and Bakker 2011), and the role played by boundary objects in fostering collaboration between teachers and researchers involved in professional development programs (Robutti et al. 2019), we analyse the effects of the joint collaboration in terms of the evolution of the boundary objects and the learning mechanisms involved. In one of the examples presented in the latterarticle, the boundary object is a set of MERLO items, which exists because teachers act on them, determining an evolution of the object (in terms of task). In this way, they influence both the community of researchers, who are pushed to analyze the new version of the task proposed by teachers in a theoretical way, and the community of teachers, who modify their practices to include new pedagogical perspectives through the use of these items.

In an effort to disseminate the idea of these items in different countries, we noted the difficulty in adapting them to different institutional contexts. A necessary work of elucidation and collaboration between teachers and researchers is necessary, which led us to consider the following research questions:

How do the interactions among participants of different communities (researchers, teachers) and of different cultural worlds transform the teachers' and researchers' practices?

How and to what extent does the boundary crossing participate in the professional development of teachers and researchers?

Interactions among researchers and teachers have been studied in mathematics education research by different scholars (Adler 2017; Aldon et al. 2017; Goos and Benisson 2017; Kynigos and Kalogeria 2012; Rasmussen et al. 2009; Robutti et al. 2019) or in a wider context of research in education (Monod-Ansaldi et al. 2019; Nizet et al. 2019). We place ourselves in this stream of research to analyze the effects of these interactions in the specific case of MERLO items.

In analyzing data based on these items produced by teachers in professional development, we used two different kinds of technologies, termed representational infrastructures and communication infrastructures by Hegedus and Moreno-Armella (2009). Belonging to the first type is the dynamic software GeoGebra, introduced to the teachers by the researchers at a certain point of their process of designing such items, as an instrument of exploration given to students implementing it in various parts. 


\begin{tabular}{|l|l|l|}
\hline TASK & STATEMENT 1 & STATEMENT 2 \\
\hline STATEMENT 3 & STATEMENT 4 & STATEMENT 5 \\
\hline
\end{tabular}

Fig. 1: MERLO item structure.

Representations of mathematical objects that would be static on paper become dynamic, which supports students in connecting meanings to oneanother. Because they were not directly suggested by the researchers who were educating the participants during the study, the evolution of such items as a boundary object was able to be studied.

To the second type belongs the platform in which teachers discuss in an asynchronous modality: their successive interventions create a context in which they participate, enriching each other with texts that not only limit to perform the task in a standard way, but adding new elements according to their experience and competences. In particular, the teachers work lean to the introduction of dynamic geometry in MERLO items. We analyze this fundamental evolution in the light of our theoretical construct.

After a description of theoretical and methodological elements, we will show this richness in teachers' interventions and how they interact proficiently. We will then discuss data for possible answers to the questions, under the use of the theoretical elements.

\section{MERLO Items: Framework and Pedagogy}

The first experience with MERLO items was in architecture at the tertiary level of education (Etkind and Shafrir 2013) and then spread out in different levels of education (both school and university) and subjects, in various countries (Arzarello et al. 2015a; Robutti et al. 2016, 2020; Shafrir and Kenett 2015; Thibault and Sinclair 2019). Such an item is a collection of five different representations of mathematical concepts in multiple sign systems. These representations are statements (see Fig. 1) that may or may not share the same meaning (Etkind and Shafrir 2013). The task for the solver is to select the statements that share the same meaning (referring to a mathematical object) and to explain the reasons of the selection. From the point of view of the designer, the statements have different roles: some of them are chosen to share a common mathematical meaning, while others have the role of being distractors. From the point of view of the solver, all the statements are representations of mathematical concepts in various registers. The solver has to select those statements (two or more) that share a mathematical meaning and explain why: this is the task in the first box of the item (see Fig. 1).

The design of a MERLO item utilizes two criteria:

- Meaning Equivalence: statements that provide different registers of representations of the same concept: e.g. the graph of a parabola and the equation of a parabola;

- Surface Similarity ${ }^{1}$ : statements that are similar in appearance and share the same register of exterior representation and possibly same signs, but not the same

\footnotetext{
${ }^{1}$ As formulated in this article, the Surface Similarity criterion is a sub-case of the formulation present in the former articles of the inventors of MERLO items (Etkind et al. 2010). This is done to simplify the use of the two criteria in designing items. Substantially, in this teacher education experience, the researchers instructed teachers in order not to apply the two criteria simultaneously.
} 
mathematical meaning. For example, two statements in natural language are designed through the Surface Similarity criterion if they use the same register, but convey different meanings, such as the graph of a parabola and the graph of a polynomial function of fourth-degree.

Using the two criteria above for designing the five statements requires choosing different registers to represent:

- a set of concepts (two to four for each item) that share a mathematical meaning according to the Meaning Equivalence criterion;

- a set of different concepts, in the role of distractors (respectively zero to three for each item) that may:

- be related to the first set by the Surface Similarity criterion;

- have no relation with the first set.

Meaning is intended in a sphere of practice, with regard to the school context related to it:

we take it that the meaning of a mathematical concept lies essentially in the situations it allows us to describe and the problems it allows us to solve in an efficient and reliable way. This viewpoint plays a fundamental role in the design of didactical situations as well as in the analysis of actual practice. (Kilpatrick et al. 2005, p. 12).

So, we do not refer to a strictly logical-epistemological correspondence, but to a larger view. For example, if one statement shows the graph of a parabola (e.g. of the equation $y=2 \times{ }^{2}$ ) and another statement represents a generic parabola in a symbolic way (e.g. the equation $y=a x^{2}$ ), then we accept as correct the choice of the student to select both statements as referring to the same concept (that of a parabola), because they are related via the Meaning Equivalence criterion. But if there is another statement representing a cubic equation (either in a graphical register or another), it cannot be selected because it is related to the parabola only via Surface Similarity, and represents another concept. In this way, we also contemplate in the sharing a more general and a more particular case.

An example of a mathematical MERLO item is in Fig. 2. The designer prepared the item choosing $\mathrm{A}, \mathrm{B}$, and $\mathrm{C}$ to share the same mathematical meaning, while the statements $\mathrm{D}$ and $\mathrm{E}$ do not share the same meaning with the other statements.

The solver has to recognize that the statements in $\mathrm{A}, \mathrm{B}$, and $\mathrm{C}$ share the same mathematical meaning, where A provides the numerical value of the fraction, and $\mathrm{B}$ and $\mathrm{C}$ are graphical representations (discrete and continuous, respectively) of the same fraction. In addition, the solver has to recognize that the statements in $\mathrm{D}$ and in $\mathrm{E}$ do not share the same mathematical meaning as statements A, B, and C, because in D there is another fraction that is similar but not equivalent to the fraction in A, while E represents a number line that indicates two integer numbers, but not their relation as numerator and denominator of a fraction. The solvers are asked only to mark the statements that share the same mathematical meaning in the item (question 1). Answering the second 


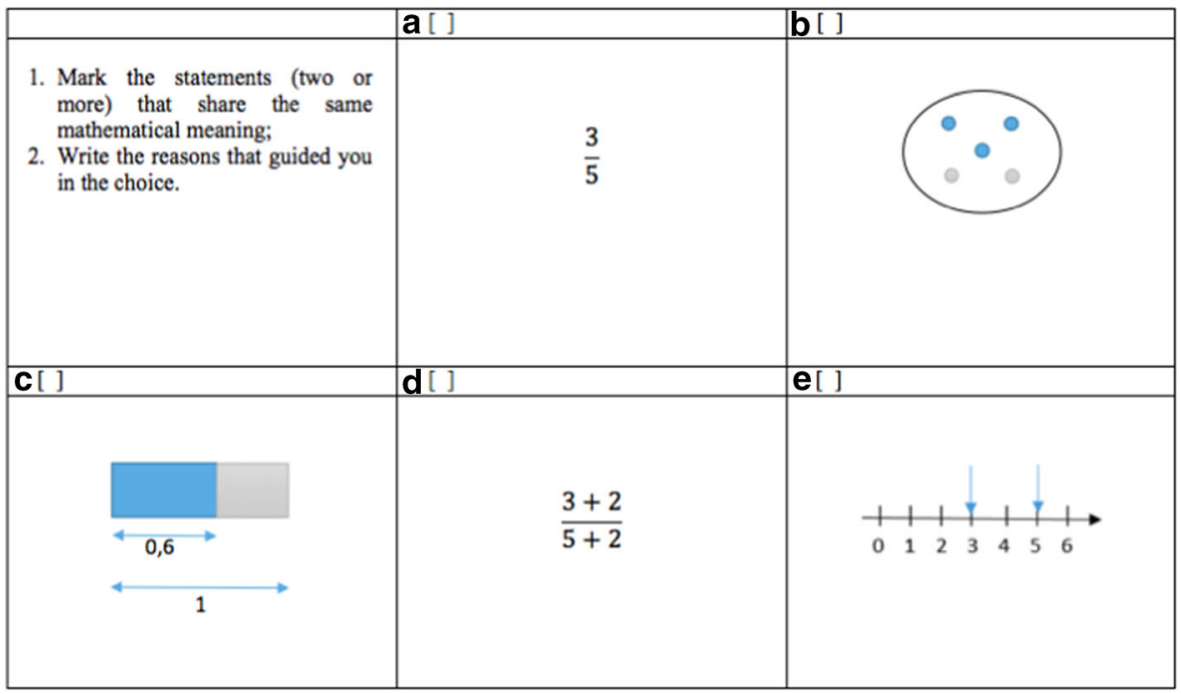

Fig. 2: An example of MERLO item about fractions in the solver version.

question consists of providing arguments to support the decisions made. Both responses to the task ( 1 and 2 ) can be evaluated (or not) by the teacher.

MERLO items can be used in several different educational actions (pedagogy, for teachers and/or students):

A. professional development activity for teachers where they are involved in solving and discussing such items;

B. research/educational activity where teachers are engaged in designing items in collaboration with researchers;

C. school-based activity where students solve and discuss these items;

D. student diagnostic assessment involving such items.

According to this list, these items are didactical and methodological tools, both for teachers' and for students' education. This article focuses on point B: research and training activity with teachers.

\section{Theoretical Framework}

One of the frameworks for addressing learning in on-line communities is to perceive learners as individuals who act in a certain community whose socio-cultural norms have an impact on meanings, interactions, and relationships between participants, knowledge, and artefacts. Different communities may act on the same objects, with partial intersection at the boundaries. We use the term 'boundary' in the sense that Star (2010) defined it, "a shared space, where exactly that sense of here and there are confounded" (p. 602). If boundaries can be seen as sources of potential difficulties, they may also offer opportunities for innovation and renewal,since they carry potential for learning when people encounter discontinuities in interaction and perspectives 
(Akkerman and Bakker 2011). Additionally, they can be a place for meeting and discussing the meaning and use that the actors attribute to it (Carlile 2004).

Crossing boundaries promotes reflection on long-standing practices, theories, and assumptions. Boundary crossings can also act as sources of deep learning because new insights and developments often arise at the boundaries between communities (Wenger et al. 2002). Akkerman and Bakker (2011) suggest that boundary crossing can entail learning through four potential mechanisms (of which we identified most of all the last one):

- Identification of a boundary: recognition of the practices of each community in relation to one another; it can appear as a process of legitimization of the coexistence of different meanings related to the boundary object; identifying a boundary is not erasing differences, but rather identifying the place where discontinuity occurs.

- Co-ordination of activity flow fostering co-operation between practices: coordination requires communication between actors, particularly aiming at translating in order to understand the different meanings that are used, and moreover to allow actors to take the others' points of viewinto account.

- Reflection on the practices and the existence of a boundary between them: this reflexive mechanism goes further and overtakes the understanding of others' viewpoints to make "explicit the knowledge and assumptions mobilized in the interpretation of the object" (Hoyles et al. 2007, p. 335). It is a process of elaboration of new perspectives aiming at informing future practices.

- Transformation where participants from different communities engage in collaboration and co-development of new practices by crossing boundaries and addressing boundary objects: transformation is the process where actors can recognize a shared problem space, one where it is possible to act simultaneously and to engage themselves in a creative process of hybridization considering the different approaches to the same object. The process starts with the confrontation, "with some lacks or problems" (Akkerman and Bakker 2011, p. 146); hence confrontation is the encounter with discontinuities that occurs at the boundary. Crystallization is a description of transformation, which denotes how learning occurs at the boundary: it can occur as the form of something hybrid that is created at the boundary and it is embedded in practice in order to have consequences.

Boundary-crossing involves going into unfamiliar territories that require the use of new cognitive tools when using boundary objects (Star and Griesemer 1989). The boundary objects are artefacts that can have meaning for two communities. Such meaning is neither completely different nor necessarily identical, but it is sufficiently adaptable for dialogue to take place and to fulfill a bridging function (Star 2010) through the support of brokers (Wenger 1998).

The introduction and creation of new boundary objects require different learning to enable the members of each community to cross boundaries, negotiate common boundary objects, develop new cognitive tools at the boundaries and reflect on how boundary objects could be adapted by and for each community. This new learning of communities has been studied in mathematics education research by different scholars (Adler 2017; Goos and Benisson 2017; Kynigos and Kalogeria 2012; Rasmussen et al. 2009; Robutti et al. 2019). 
Finally, following teachers' and researchers' actions on MERLO items as objects at the boundary of the two communities, a crystallization can occur and a particular item reaches a stable version (in this particular case, at least).

We locally consider the cognitive actions on boundary objects by referring to Carlile (2002, 2004), who paid close attention to concrete and localized knowledge and development practices, considering boundaries encountered in the area of knowledge. Following Carlile (2004), the management of knowledge at the boundary is the result of three distinct kinds of activity.

- Transfer and translation: situations where the actions on the boundary object define a common lexicon between protagonists (transfer) and facilitate explanation and confrontation of points of view (translation). The boundary object becomes a 'cognitive' mediator that constitutes a transaction zone for the respective perspectives in a semantic way.

- Transformation: when the interests of participants diverge and when there is negotiation of interests and knowledge, yielding to the construction of a compromise, in order pragmatically to be used. Hence, "the boundary object becomes a 'social' mediator since there are issues of power and allegiances, exchanges of contributions and identity" (Trompette and Vinck 2009, p. 13).

Confusion can occur because of the same word (transformation) being used as a mechanism and a process (in the approach of Akkerman and Bakker 2011) and as a cognitive action on the boundary object at stake (as defined by Carlile 2004). In the following, the term transformation will mainly be used in the sense of a process. We will indicate when it refers to a cognitive action, by means of quoting Carlile.

The study was directed at the analysis of a first (international) crossing of the MERLO object that passedinstitutional boundaries (Italy and Australia), and of a second crossing of the same object -inside the Australian institutional community that passed methodological boundaries (from static to dynamic representations). In particular, we attended to the actions on the objects and the process of transformation in the community of teachers.

\section{Method}

This study was part of a larger design-based research project, in the sense of Cobb et al. (2003). This larger project tested how MERLO items could be used in teachers' practices. We used design-based research because it was particularly suitable for studies that include iterative interventions that are complex, interactive, and reflexive in nature (Schoenfeld 2006). The research presented here was inspired by Italian work on MERLO items at the University of Turin (Arzarello et al. 2015b; Carante 2017). Since 2015, it has been drawing on data from the Meaning Equivalence Reusable Learning Objects (MERLO) project by researchers from the University of Turin in Italy and the University of New Englandin Australia. The people involved are researchers from these two universities, a $\mathrm{PhD}$ student from Italy, and in-service Australian teachers in a professional development program. 
The study reported here is exploratory in nature and focuses on the MERLO items designed by 36 Australian in-service secondary school mathematics teachers, who teach Year 7 to Year 10 secondary mathematics. These teachers were recruited from ten private secondary schools in New South Wales, during a professional development course. The aim of this course was to enable teachers to design tools that will help their students solve National Assessment Program - Literacy and Numeracy (hereafter, NAPLAN) assessment exercises.

The teachers who participated in this research studyhad volunteered to attend the professional development course. All participants had extensive experience teaching mathematics at the secondary school level and were aware of students' needs and difficulties in the learning of mathematics, taking the mathematical knowledge for teaching, the instructional dimensions and constraints, the teaching practices at school, the main needs for students and so oninto account.The researchers (the Australian author and an Italian PhD student), acting as educators, supported teachers both theoretically and practically during and after the design of MERLO items.

The professional development course took place in Australia in two phases.

1. Face-to-face meetings attended by the Australian author, the Italian $\mathrm{PhD}$ student and the Australian in-service teachers. At the beginning of the first meeting, the participating teachers were introduced to a list of MERLO items that had been developed by in-service mathematics teachers in Italy. They were asked to work individually or in pairs to solve the tasks as if they were students: 1) identify the statements (two or more) that share the same mathematical meaning (that is, the Meaning Equivalence criterion) among the given five different representations; 2) discuss the reasons that guided them in making these decisions, and 3) discuss solutions with the instructors. The role of the researchers was restricted to coordinating the discussions around the Italian examples of the items. The researchers and the participating teachers were prompted to discuss all the meanings that appear in all of the five statements in each item, trying to link them to the mathematics curriculum in Australia.

2. Remote work on a platform consisting of a questionnaire about MERLO pedagogy (about ten minutes) and interactingwith on-line tasks on the production of MERLO items, according their educational interests. The questionnaire contained eighteen questions, and consisted of four sections: interest; usefulness for teachers' professional development; effectiveness for students; implementation in the Australian class. A three-point scale (agree, undecided, disagree) was used for each question. Additionally, teachers were asked how many years they had been teaching and which class years they had taught. The questionnaire also included open questions, such as, 'What kind of MERLO activities do you suggest?'. The questionnaire asked teachers to list the strengths and weaknesses of the MERLO items, in order to let them be aware of the didactical potentiality of this tool. When they returned back to their school, the teachers explored using such items in their own classrooms, either those presented during the course or designing new ones. The teachers designed new items based on the Australian curriculum (ACARA 2019) or the national assessment (NAPLAN), and then uploaded them to Google Drive. They participated in on-line discussions about their items with the other teachers and the Australian researcher. The discussions were based on design strategies, on 
their didactical choices, on their reasons based on the national curriculum and on assessment.

In this article, we report on analyzed data from (a) the data from the questionnaire and (b) the messages exchanged during the on-line communication amongst the Australian educator and the mathematics in-service teachers, as well as the files attached (worksheets, MERLO items, written explanations and justification of the process of desiring such items, articles, etc.; 713 messages and 154 attached files were included in the analysis). We chose, in this article, to focus on a particular mathematical subject, in the domain of geometry, for two reasons: first, the evolution of the items is significant with respect to the results of the actions on boundary objects, starting from a syntactic approach of the items and then going to a pragmatic level of description through a discussion of the meaning of the item within a school context. And second, the MERLO item, as a boundary object, is deeply transformed by the fundamental characteristic of DGS - its dynamism - as well as by the possibility of linking different representations of the same mathematical object. Didactical, cognitive and educational advantages of using dynamic representations are well fromthe literature (e.g. Arzarello et al. 2002; Sinclair and Robutti 2012).

The messages and attached files were numbered in progressive sequence and coded. For the purpose of data analysis, we initially grouped them by themes with respect to the issues they addressed (for example, a specific epistemological topic, a kind of representation or the role of a representation in a MERLO item). We considered a singlesuch item as the unit of analysis and these units were chronologically organized and formed respective discussions. We attempted to discern regularities in patterns of interactions (Yackel and Cobb 1996) or patterns of meanings in each discussion or across discussions.

After a cross-analysis by researchers, we distinguished two thematically coherent sequences of comments and exchanges around the following categories:

- design of one MERLO item (on areas);

- discussion to explore didactical issues related to the contrast between static and dynamic (when GeoGebra was used by the designer and by the solver) MERLO items, related to the item at the previous point.

We first selected a set of four discussions around four different items about different topics: statistics, arithmetic, algebra and geometry. Among them, we decided to opt for the discussion around the one dealing with geometry, because it had two particularly interesting aspects: the fruitful interaction among teachers on the design of an item and the introduction of a new tool not presented by the researcher in the course (the dynamic role of representations). To present this discussion, we organized it into five vignettes that illustrate the rich interaction among the teachers and show a crucial change in the item by including dynamics. These vignettes are particularly interesting for the study because they mark an activity of the community of teachers that influenced the community of researchers on the introduction of something new, not previously present in these items.

Below, we present each of these vignettes in turn and then we discuss and analyze the recurrent meanings appearing in the exchanges pertaining to the teachers' reflection 
and justification of the didactical value of the MERLO item under discussion, their understandings for using the item in their teaching practices, how they relate the item to the content they teach, and the didactical challenges of the item according to their structure.

\section{Data Analysis}

During Phase 1 of this project, the participating in-service Australian teachers were given documents containing instructions for creating MERLO items and a set of eight examples of these items (developed by an Italian community of teachers), two on each of four topics: geometric concepts, algebra, trigonometry, and calculus. The participants generally expressed an appreciation towards the potential of these items. When asked to list positive aspects of the items, they mentioned: strengthening the students' awareness of drawing connections between concepts; supporting students' connections among different representations of concepts; promoting connected learning of mathematics. The weaknesses they mentioned included: "some of the ideas will be beyond some students and others will struggle with the literacy component"; "some students might react because MERLO activities are a novel way of teaching and assessing knowledge"; "some teachers will have difficulties with designing MERLO activities". Every participant designed one MERLO item and, for the purpose of this article, we selected an item that started a rich discussion on the manner (static/dynamic) of presentingit to students.

We now present five vignettes, with descriptions andinterpretations. These vignettes do not come from consecutive excerpts.

\section{Vignette 1}

In the questionnaire, Martin had responded that he found MERLO items interesting and that he was involved in their design and solution. However, as he said, "I am undecided about whether I enjoyed solving and creating MERLO activities, because it was not always easy to create similar representations for the target statement". ${ }^{2}$ He answered positively on all the questions about the usefulness of such items for teachers' professional development and he emphasised that thesetasks helped him gain a deeper understanding of the mathematical concepts he teaches. He also agreed with all the questions regarding the effectiveness of the items for students, but he was undecided about the implementation of such items in the classroom, because it was proving challenging for him to create different representations that share the same meaning. Martin's item (see Fig. 3) was the occasion for an asynchronous discussion on the different statements of the MERLO item.

1. Martin: I first review the curriculum content I wanted to teach that was the area of rectangles and squares. I thought that it would have been more beneficial for the students if I provided them with a scenario around those concepts.

2. Anna: What do you mean?

\footnotetext{
$\overline{{ }^{2} \text { Here, he intended the statement }}$ from which he began the construction of the item.
} 


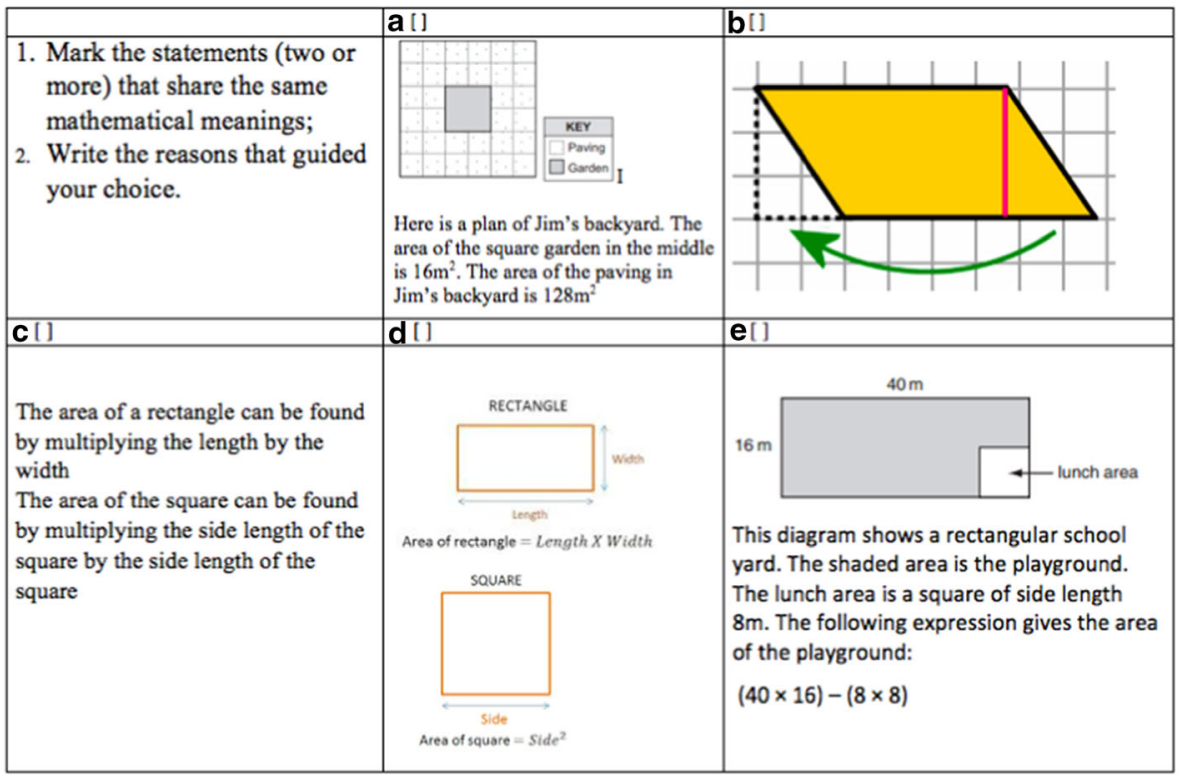

Fig. 3: Martin's MERLO item. (The language used here to express the area of a square as side $^{2}$ can be interpreted in the sphere of practice of a community of teachers discussing of a task for their students, even if not completely correct epistemologically speaking.)

3. Martin: [Uploaded his MERLO item] I mean that my scenario relates the areas of rectangles and squares to a familiar environment of the students. Statements A and E, both were formulated based on questions, from previous NAPLAN tests that are applications of the areas in real life.

4. Researcher: Your MERLO item with these two statements [A and E] promotes the involvement of the student with the calculation of the area of the paving in Jim's backyard [statement A] and the formulation of the expression that gives the area of the playground [statement E].

5. Martin: Yes, exactly.

6. Anna: You included mathematical theory too.

7. Olivia: Statements C and D.

8. Martin: I did in order to remind students how we calculate the area of a rectangle and the area of a square using words and shapes and algebraic expressions.

This discussion was introduced by Martin, who was looking at the national curriculum and selected a concept to focus on for designing his MERLO item: "area of rectangles and squares" (turn 1). Martin had had five years of experience as a mathematics teacher in a public secondary school situated in Sydney. He considered the choice of this concept "beneficial" for the students, maybe because they can feel comfortable with it. Uploading his item, Martin was more precise: the concept of area (of rectangles and squares) is a familiar environment for the students. Then (in turn 3), Martin explained the reason of the statements $\mathrm{A}$ and $\mathrm{E}$ both developed from questions of the national assessment (NAPLAN test 2008: questions 17 and 27 from Year 9 Numeracy, calculator allowed): they are applications of geometric area in real-life contexts. 
At that moment, he acted on the boundary object in a transfer action (Carlile 2004), putting in relation the institutional context (NAPLAN tests), his own teaching habits explaining the importance for students of a "familiar environment" and the type of tasks of the MERLO items. The action on the boundary object continued in this mode through the interventions of the researcher, Martin, Anna, and Olivia. They continued to connect the different elements, taking the didactical issues and the design of these itemsinto account. Martin (turns 5 and 8) answered to colleagues' and researcher's interventions with some comments on the other statements: statement $\mathrm{C}$ says how to calculate the area of a rectangle and a square, while D shows the diagrams of a rectangle and a square and how to calculate their area. Statement B refers to the area of a parallelogram and acts as a distractor. In Martin's mind, the students should first recognize that the statements $\mathrm{A}, \mathrm{C}, \mathrm{D}$ and $\mathrm{E}$ share the same mathematical meaning (area of squares and rectangles), but not $\mathrm{B}$, and second it should motivate this recognition in terms of reasons that support their choices.

Among the teachers interacting after the presentation of Martin's item, a phenomenon of confrontation (in the sense of Akkerman and Bakker 2011) took place, around the different statements he showed. The confrontation was the initial step for a bigger phenomenon, that of transformation (also in the sense of Akkerman and Bakker 2011). This phenomenon continued in the next excerpts, when a new teacher intervened. Exploration and discussion of the teacher around the MERLO item as an object was at the beginning.

\section{Vignette 2}

1. George: [Uploads a screenshot - Fig. 4 - from GeoGebra] I think it is better to include a statement in your MERLO item that shows how we can move from static shapes to dynamic ones. If my MERLO item was about the area and the perimeter of a rectangle, I would have had as statements B, C, and D [the statements shown in Fig. 4].

2. George: For B, I would have had the rectangle that is shown first on the left-hand side of the figure. It would have been good if the students were able to drag the point $\mathrm{C}$ and, at the same time, were able to observe the change of the shape of the rectangle, and the variation of the perimeter and the area of the rectangle.

3. Researcher: So, will you also replace statements $\mathrm{C}$ and $\mathrm{D}$ with the following?

4. George: Yes.

5. Researcher: Why?

6. George: Because, the middle figure that will replace Martin's statement $\mathrm{C}$ shows the function of the varied area and width of the rectangle. It would be a very good distractor statement. I will replace Martin's statement D with the spreadsheet that displays the length, height and area of the rectangle. It is a pity that it will show the changes in a static form. I wish we were able to click on the 'Capture Data' and observe those changes in a dynamic form while we move the point $\mathrm{C}$ and the spread will be completed with the varied length, width and area data.

7. Researcher: If you have to design your own MERLO item, how will you design it?

Looking at Martin's item, George - who had had twelve years of teaching experience in a Catholic secondary school situated in a rural area - intervened in the 


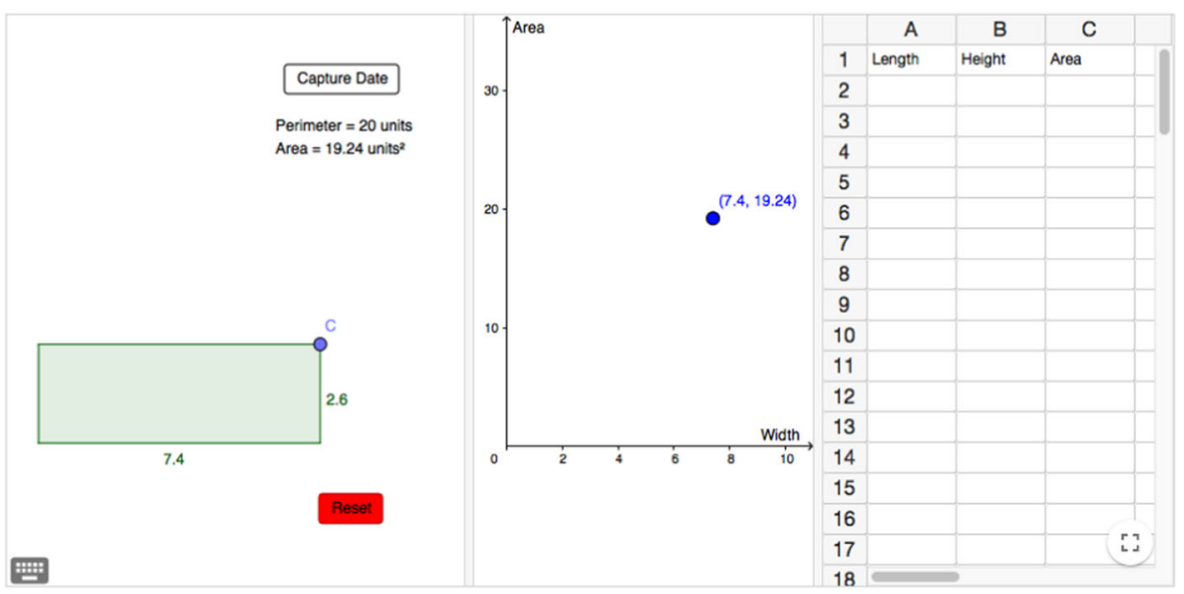

Fig. 4: Screenshots by George (new statements B, C and D).

discussion, by posting a comment. In the questionnaire, George answered positively to all the questions regarding the interest related into the MERLO items. He also agreed about the usefulness of thesetasks for teachers' professional development, because they helped him to understand better the target mathematical concepts he teaches and also enabled him to teach his students how to represent the same mathematical concept using different mathematical representations. Additionally, he responded positively on all the questions regarding the effectiveness of the MERLO items for students and the implementation of the MERLO items in his classroom and in Australian schools in general.

George's comment introduced a new element: the dynamism which gives a new meaning to the item, even if the structure is not modified. George seemed to have a strong sense of being part of a community (see turn 9): "I think it is better to include a statement in your MERLO item that shows how we can move from static shapes to dynamic ones" (our emphasis). This belonging to a community that can be considered as an institution is important for the analysis of boundary objects, because George acted on the objects (here, the items) from a particular viewpoint directly linked to his belonging. He wanted to change something in the item and provided a suggestion, in order to modify Martin's item to obtain a better version, from the point of view of students' exploration of meanings. He proposed to colleagues a new item, obtained by changing three statements (B, C and D) from Martin's item. In doing this, he was acting in a semantic way with a view towards pragmatic action (in the sense of Carlile 2004) on the items that he will transform and use, including this dynamism. According to him, the new element in the item "shows how we can move from static shapes to dynamic ones" (turn 9).

Confrontation, in the sense of Akkerman and Bakker (2011), that began in the previous turns, continued in these excerpts: George was thinking that, even if the structure of the item should be the same, there is the possibility to do more in the item if using dynamic representations. What he suggested and introduced (see Fig. 4) are three different representations made in GeoGebra: in the first one, there is a rectangle draggable from one vertex; in the second, a function in Cartesian plane with width and area (of the rectangle of the first representation) as independent and dependent 
variables; in the third one, a table to collect values of length, width and area of rectangles.

For him, there was dynamism in more than one way: "it would have been good if the students were able to drag the point $\mathrm{C}$ and at the same time, were able to observe the change of the shape of the rectangle, and the variation of the perimeter and the area of the rectangle" (turn 10). He intended the possibility to observe dynamismin each box, but he also thought that each box should be linked to the others: the second box to the first, and also the third - in this way, so that dragging could be done and seen in the first box that would also cause changes in the other boxes.

At this point, George's action was questioning some features of the item'sstructure, in the sense that it broke the independence of the statements. It acted in a translation action. The justification that George gave leans on the didactical justification that we can imagine as habitual for him: in George's mind, "It is a pity that it will show the changes in a static form" (turn 14). For this reason, he introduced the new element of dynamism. Finally, the researcher asked George how he would do his MERLO item. And this question is particularly important in this process of asynchronous interaction among teachers.

At this step of the interaction, we can see that, in the teachers' community, George is a member who acts as a carrier of novelties:

- the topic is now area and perimeter of rectangles (for Martin, the topic was area of rectangles and squares);

- some representations are dynamic;

- some representations are linked together (or should be linked).

- Meanwhile, George was not interested in changing the overall structure of the MERLO item:

- the task remained the same (1. Mark the statements ... 2. Write the reasons...);

- the item was made of five different representations;

- the topic was strictly related to national curriculum and assessment (as institutional references).

The researcher, in that excerpt, asked the teacher to make the design explicit, in order to assure that the MERLO item's structure was maintained. In this confrontation phase, the researcher played the role of broker, favoring the explanations and an internalization of novelties within a given structure.

\section{Vignette 3}

After one day, George uploaded the following item [Fig. 5]:

1. George: Well, here is my MERLO item.

2. Researcher: Could you please explain to us if you used any of the eight examples of MERLO items that I provided you with?

3. George: I used only the instructions about theory that you gave me. I read those instructions about the statements of the MERLO items and I also studied the example of MERLO items which were related to geometry.

4. Researcher: What did you think when you created this MERLO item? 


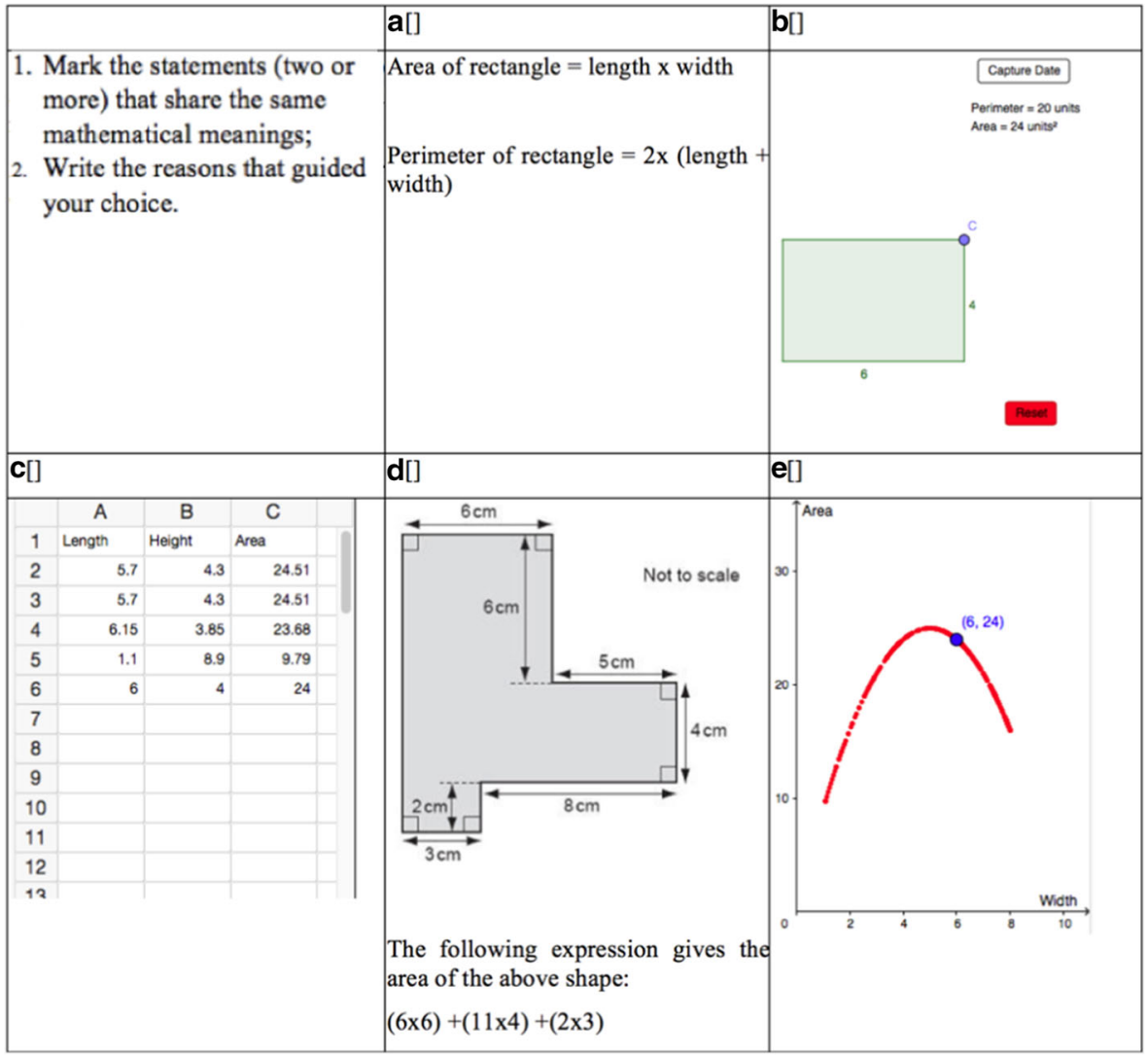

Fig. 5: George's MERLO item.

5. George: Well, I started with the shape of a rectangle and the formulae that we use to calculate the area and the perimeter of a rectangle. Statement A shows the formulae and the static shape of a rectangle and then I moved from the static shape that is a rectangle with constant dimensions to a dynamic one. Statement B shows that by moving the point $\mathrm{C}$, the dimensions of the rectangle that is length and width are varied. Statement $C$ shows the varied area and perimeter of the rectangle. At the same time, while the length, the width and the area of the rectangle are captured and presented in a Table. I chose a table to capture the data because a table facilitates representation of data in an attractive, easy to read and organized manner. Then, I reviewed some exercises from NAPLAN tests and I chose a complicated shape that it was included in a NAPLAN test 2008 [question 14 from Year 7 Numeracy, non-calculator allowed]. In the NAPLAN test, students were asked to choose the correct answer regarding the perimeter of the shape. In my statement D, students were asked to provide the expression, which gives the area of the shape. The last statement, statement E, represents the area and width. It acts as a distractor that shows the two-dimensional variation in the Cartesian plane, 
by plotting the area and the width as they change, knowing that the perimeter is constant.

The intent expressed by George in the previous vignette is made concrete here. Through the example he gave, George (turn 20) explained in details a technique of design for MERLO items:

1. To look at the mathematical concept: "I started with the shape of a rectangle and the formulae that we use to calculate the area and the perimeter of a rectangle" (turn 20).

2. To look at the possible dynamic representations of the mathematical object.

3. To assure that the proposal is coherent with the institutional framework he works in ("In the NAPLAN test were asked to choose the correct answer regarding the area of the shape. In my statement D, students were asked to provide the expression, which gives the area of the shape.")

4. To assure that the MERLO item justifications are correct ("The last

statement, statement E, represents the area and width. It acts as a distractor that shows the two-dimensional variation in the Cartesian plane by plotting the area and the width as they change, knowing that the perimeter is constant.")

At that point, George acted on the boundary object at a pragmatic level, projecting its design activity to a level of generalization. The dialogue came back to the way George built his items. He explained that he used only the justification of the items that he understood from the researcher. It is an interesting example, where a pragmatic action on the boundary object modified the meaning of the item to the researcher. The action on the boundary object was at a pragmatic level, because there was a projection towards the use of dynamism within the MERLO items and an effective modification and, hence, we can speak of transformation in the sense of Carlile.

The process of confrontation, that had begun in the dialogue one day before, was now going on with George's new item, in which he only used "the instructions about theory" (turn 18). According to Akkerman and Bakker (2011), the meaning-generating effect of diversity cannot be anticipated: George was not asked to introduce a change in the item. The differences he introduced marked the beginning of a negotiation of meaning inside the item about its static/dynamic version. The role of the researcher, here, was delicate, in fact: "group members should be encouraged to perceive and treat each other as other persons and to render each other's arguments as strange and new" (Akkerman et al. 2006, p. 482).

Here, the researcher was stimulating George in explaining his choices and changes to his colleagues. In doing so, he began a new phase in the process of transformation: the recognition of a shared problem space, in direct response to the confrontation phase. The process of confrontation, stimulated by questions and comments of the researcher, that had been developed in the recognition of a shared space, made of MERLO items containing dynamical representations not only per se, but in virtue of their connections through common variables that linked changes in one representation to changes in the other. "Transforming current practices is not without direction; it is 
motivated by and directed toward the problem space that binds the intersecting practices together" (p. 148).

The following vignette directly leads on from the end of Vignette 3.

\section{Vignette 4}

1. Researcher: Excellent.

2. George: I would also like to mention that I attempted to use different representations to represent area in the statements of my MERLO item including the implementation of dynamic statements.

3. Jenny: I like your MERLO item George. I also created different representations of data frequencies, tabular and graphical representations. I did not think to make those statements dynamic, but it could have been great if those statements were dynamic and change every time I plot a different data set.

4. Researcher: Could you please talk about your MERLO item and explain what you referred to, in order to design your MERLO item?

5. Jenny: I did not use in my classrooms any of the MERLO items that you provided me with during the professional program. I used those items only for myself as a guide to understand how to design MERLO items. When I started designing my MERLO items, I reviewed the content of the Australian curriculum and the NSW syllabus. I used primarily the national curriculum and the state syllabus as a point of my reference to revise with my students the mathematical knowledge of the previous schooling years. I did not read any previous NAPLAN tests to design the statements of my MERLO item.

In this excerpt, the researcher simply approved ("Excellent"), giving a positive evaluation that encouraged George to continue adding the possibility of givingthese items a dynamic structure: "I would also like to mention that I attempted to use different representations to represent area in the statements of my MERLO item including the implementation of dynamic statements" (turn 22). He continued a pragmatic action on the boundary object, adding this property, which was also mentioned by Jenny as a new possibility (turn 23). At that moment, the discussion changed, due to the researcher who asked Jenny to explain her design of MERLO items. The researcher highlighted the novelty of the design but gave an agreement on the boundary crossing by asking for a description of "your MERLO items"; by this expression, she agreed to the fact that the new design still fits this item design.

As in the previous vignette, it seemed that there was a phenomenon of modification of the researcher's point of view, as well as of Jenny's point of view. Jenny, as well as George, understood and used the fundamental ideas of the MERLO items (taken from the Italian examples), but she adapted them according to Australian institutions: "I used primarily the national curriculum and the state syllabus as a point of my reference to revise with my students the mathematical knowledge of the previous schooling years" (turn 25). It seems that Jenny felt the need to design her own items, in order to appropriate this new teaching practice into her own, because the Italian MERLO items were not well-suited for the Australian curriculum.

At the same time, this excerpt shows a first instance of the phenomenon of hybridization (in the sense of Akkerman and Bakker 2011), when the actors engage 
in a creative process, in which hybrid cultural form emerges from the traditional ones. This was the case here, after George's presentation: "I also created..." (turn 23). As well as the transfer and translation actions that led to a transformation (in the sense of Carlile 2004), we can see a beginning of crystallization (in the sense of Akkerman and Bakker 2011), when George and Jenny explained that they could use the MERLO items on their own, and use them in their own practices.

It is interesting to note that the two levels of boundary crossing announced above are present in the same discussion: first, with transfer and translation actions, the MERLO items, considered as a boundary object, are adapted and put into their hands in the Australian institutional context. Second, with a transformation action, the MERLO items are proposed within the Australian community of teachers, who discussed the possibility of a new type of item, crystallizing the created objects, and using them in their own practices.

\section{Vignette 5}

After seventeen days ...

1. Judith: I liked so much the MERLO item of George because he included dynamic statements and I used it today with my students. They were excited.

2. Jenny: I also used it with my students. They love it. My students asked me to create more MERLO items that include dynamic statements.

3. Judith: The more dynamic statements the MERLO items include, the better it is for our students' comprehension of mathematics.

4. Researcher: Why?

5. Jenny: Because the students interact directly with the statements by altering sliders or entering values and at the same time observe the impact of their changed on the graphs or formulae. Mathematics symbols, graphs, formulae became a live organism manipulated by students.

6. After fourmore days ...

7. Jack: I used it too. It seems that I need to create only dynamic MERLO items from now on and use them when I teach.

8. Murray: I used it too. Let us create some dynamic MERLO items and exchange them between us.

In this vignette, the crystallization towards integrating the MERLO item with dynamic features in their teaching practices (turn 26, 27, 28) was going on, and teachers were including dynamism within their MERLO items that embodied the dynamic statements as they hadinitially been created by George. The use of dynamic features showed how the emergence of a community of school teachers represented a successful form of boundary crossing, while Judith, Jenny, Jack and Murray (turns 26-32) started to enact dynamismin these items used in their own teaching practices. Vignette 5emphasisescrystallization by pointing at the transformation process of MERLO items. What also is revealed in this vignette is the achievement of the transformation in the sense of Carlile: MERLO items are now an element of the set of didactical tools that teachers can call forth,provided they includedynamism. It means that the 'new' items fit the institutional demands and are coherent with the teachers' teaching methods. 


\section{Discussion and Conclusion}

An important element in these interactions among teachers was the role of the communication infrastructure (in the sense of Hegedus and Moreno-Armella 2009), that enabled the participants to communicate asynchronously, reading the threads and responding according to their availability. These Australian teachers would never have had the opportunity to be a community without the existence of the platform that promotedcommunication among them. The teachers were focused on the design of MERLO items that provoked expressions of mathematical and didactical ideas in their textual exchanges. They had the opportunity to store these items at a given time and to reflect on them, using them in their teaching practices or changing them, according to the contextual factors of their classroom activity. In the data shown here, we observed ways in which mathematics teachers were engaged in professional development- in this instance, the design of their items - using the platform as a communication infrastructure with its affordances. The affordances of this infrastructure as a communication tool integrated the potentiality of the dynamism introduced by GeoGebra in the MERLO item and provided the teachers with opportunities to interact together quickly and directly on their tasks.

The Australian teachers were taught about such items, how they are structured and how they can be used in class, and were also challenged in using these particular items in their classes. They were introduced to such items produced by an Italian community of teachers. The passage from Italian to Australian institutional contexts was not a simple use of Italian items by Australian teachers; it was something more. For this reason, we identified a boundary crossing that was not only geographic, but also institutional and cultural in its essence: the Australian teachers needed to use their national curriculum and national assessment as reference for designing items to be used in their school context.

Teachers appropriated MERLO items and, in their specific context, enlarged their set of resources feeding into their teaching practices. Even if not sufficiently discussed here, this crossing was fundamental and could be interpreted in light of cultural transposition (Mellone et al. 2019). However, these teachers maintained the structure (invariant elements: task, five statements, different representations, criteria of meaning equivalence and surface similarity), while changing the institutional context. Boundary crossings that were analyzed in the previous section were about adding new representations brought by DGS properties and about taking the curriculum and institutional recommendationsinto account. These invariant elements constituted the robust (Star and Griesemer 1989) part of the item considered as boundary object.

What we saw in this study was that the crossing was not neutral when it occurred, but rather it deeply influenced the practices of the community: the Australian teachers took for granted the robust part of the boundary object and modified the other, related to their context. This is the important result of our findings: if, according to Wenger (2010), some boundary objects find their value, not just as artefacts of one practice, but mostly because they support connections between different practices, in this study we found that the boundary object was a promoter of the introduction of new practices in the community of teachers. They were engaged in new practices that they invented for the occasion of designing MERLO items in their context, which consisted of looking for a concept in the national curriculum or analyzing national assessment tasks. 
These two practices were extremely important in their didactics: they referred to them and shared them more times in the dialogues about the platform and agreedto consider both as central for grounding the (new) MERLO object in their (old) teaching activity. The reaction to the introduction of the new tool to the Australian teachers was quite similar to what happened two years before in the community of Italian teachers, when they received some MERLO items designed by a Russian community and wanted to frame the tool in their Italian institutional context (Carante 2017; Robutti et al. 2020).

Moreover, inside the Australian community, a second boundary crossing (one not based on a cultural transposition, but of different kind, based on the use of technology) also happened, thanks to the interventions of George: he changed some statements from static to dynamic. Again, he was taking for granted the robust part of the boundary object: its structure (task, five statements, different representations, criteria), and also the institutional context in this instance, because the item came from an Australian colleague (Martin). So, it was a crossing somewhat different from the previous one.

George also accepted the content of the item, changing it a bit (from area of rectangles and squares by Martin, to area and perimeter of rectangles) and the statements, but proposed to substitute some static representations with dynamic ones, leaning on his familiarity with DGS and his beliefinthe didactical impact on geometrical knowledge. His motivations were based on a willingness to offer students the possibility of exploring by altering the given configuration. Again, as in the first crossing, this one influenced the teaching practices of the teachers, because they recognized the utility of this dynamic feature in the item and welcomed it, transforming their practice with a hybridization process that, in some cases, crystallized (using the terminology from Akkerman and Bakker 2011).

The new practice of designing dynamic statements, along with the old one of designing static statements, can survive together in the process of creating MERLO items and can be used in an integrated way. In that sense, the boundary crossing participates in the professional development of teachers through the interactions among participants. At the same time, these interactions led researchers to take the institutional and social context of the studied environment better into account andalso, in that way, led them to participate in the professional development of researchers. But something more occurred: the epistemological nature of the item, due to the dynamic representations, changedsomewhatbyalso includingtheir variation in the topic of areas and perimeters. In some statements, in fact, there was the possibility of exploring and passing through different cases of the same representation, looking for relationships among variables. This is a feature not present in static representations: the added value of DGS.

According to Wenger (2010), "even when communities of practice live and define themselves within an institutional context, their boundaries may or may not coincide with institutional boundaries. And even when communities of practice are formed more or less along institutional boundaries, they entertain all sorts of relations of peripherality that blur those boundaries. Institutional boundaries draw clear distinctions between inside and outside. By contrast, boundaries of practice are constantly renegotiated, defining much more fluid and textured forms of participation" (p. 131). For that reason, in the first crossing,we can consider two communities according their institutional 
boundaries (Australian and Italian school systems) and, in the second crossing, the same institutional community (Australian), but with a re-negotiation of practice (dynamic vs static).

The two boundary crossings that took place are fundamental for two reasons: first, they influenced a change in the practices of the teachers (as described above); second, they offered a deeper insight from the researchers' point of view, because we can consider teachers using different kinds of interactions, based on the frames of Akkerman and Bakker (2011) and of Carlile $(2002,2004)$. The side of researchers, even if not deeply analyzed here, is another result of the two crossings: researchers gained the awareness that it was not a simple transfer of items from one institutional context (Italian) to another (Australian) that gave the possibility of a successful professional development, in terms of changing practices. And, moreover, researchers also changed their practices: on the side of research, they began to study boundary crossing to understand better the passage of objects from theoretical construct to pragmatic use and, on the side of teachers' professional development, they gained by adding to the theoretical viewpoints the pragmatic visions of the use of the object in classroom practice.

The collaborative co-development of new practices that cross community boundaries shows a process of transformation that can be described firstas a confrontation with something new and possibly useful inside the practices of the teachers; then,as a recognition of a shared problem space - that statements could be dynamic rather that static - and finally the hybridization (that is, a MERLO item with some static and some dynamic statements), which could become a crystallization in certain cases.

In this article, MERLO items as boundary objects have provided the occasion to describe the phenomenon of boundary crossing both between different communities and inside a single community, and to relate this crossing to changes occurring at the boundary object, as well as at the participants' practices. What seems interesting to develop further is studying the kind of changes in the teachers' practices within an appropriate theoretical framework on communities, such as the meta-didactical transposition or the different levels of emergence from the micro-level to the macro-level of their professional development (Prodromou et al. 2018).

Dynamic MERLO items could offer a new positive impact on students' learning and, since this experiment startedin 2015, Italian and Australian teachers have been using them in their lessons to promote deep understanding in mathematics. What is new in this example of teachers' professional development is the role of protagonist assumed by teachers in suggesting innovation to researchers and proposing dynamism as a fundamental component of MERLO items. In other studies, the researchers propose this novelty to teachers (e.g. see Thibault and Sinclair 2019) and discuss the possibility for the teachers of using dynamismto design new items.

Finally, it is interesting to notice that the evolution of the MERLO items came from the fact that DGS was strongly embedded in these teachers' teaching principles, as well as in the curriculum recommendations: a representation of a geometrical concept gains when using the dynamic property of the DGS that reveals the invariants of a particular configurations, as well as the relations between different lengths. The DGS culture enriches these MERLO items in the phenomenon of boundary crossing, by mixing the 


\section{well-known and widely used properties of DGS with a new form of mathematical questioning.}

Acknowledgements Open access funding provided by Università degli Studi di Torino within the CRUICARE Agreement.

Open Access This article is licensed under a Creative Commons Attribution 4.0 International License, which permits use, sharing, adaptation, distribution and reproduction in any medium or format, as long as you give appropriate credit to the original author(s) and the source, provide a link to the Creative Commons licence, and indicate if changes were made. The images or other third party material in this article are included in the article's Creative Commons licence, unless indicated otherwise in a credit line to the material. If material is not included in the article's Creative Commons licence and your intended use is not permitted by statutory regulation or exceeds the permitted use, you will need to obtain permission directly from the copyright holder. To view a copy of this licence, visit http://creativecommons.org/licenses/by/4.0/.

\section{References}

ACARA. (2019). The Australian curriculum mathematics. Sydney: Australian Curriculum, Assessment and Reporting Authority. http://www.australiancurriculum.edu.au/mathematics/curriculum/f-10?layout=1.

Adler, J. (2017). Mathematics discourse in instruction (MDI): A discursive resource as boundary object across practices. In G. Kaiser (Ed.), Proceedings of the 13th international congress on mathematical education (pp. 125-143). Cham: Springer.

Akkerman, S., Admiraal, W., Simons, R., \& Niessen, T. (2006). Considering diversity: Multivoicedness in international academic collaboration. Culture \& Psychology, 12(4), 461-485.

Akkerman, S., \& Bakker, A. (2011). Boundary crossing and boundary objects. Review of Educational Research, 81(2), 132-169.

Aldon, G., Cusi, A., Morselli, F., Panero, M., \& Sabena, C. (2017). Formative assessment and technology: Reflections developed through the collaboration between teachers and researchers. In G. Aldon, F. Hitt, L. Bazzini, \& U. Gellert (Eds.), Mathematics and technology: A C.I.E.a.E.M. sourcebook (pp. 551-578). Cham: Springer.

Arzarello, F. (2006). Semiosisas a multimodalprocess. Revista Latinoamericana de Investigación en Matemática Educativa, 9(1), 267-299.

Arzarello, F., Kenett, R., Robutti, O., Shafrir, U., Prodromou, T., \& Carante, P. (2015a). Teaching and assessing with new methodological tools (MERLO): A new pedagogy? Paper presented at the IMA International Conference on Barriers and Enablers to Learning Maths. Glasgow: Institute of Mathematics and its Applications. https://iris.unito.it/retrieve/handle/2318/1580275/180494 /Arzarello\%20et\%20al..pdf.

Arzarello, F., Olivero, F., Paola, D., \& Robutti, O. (2002). A cognitive analysis of dragging practises in Cabri environments. ZDM: The International Journal on MathematicsEducation, 34(3), 66-72.

Arzarello, F., Robutti, O., \& Carante, P. (2015b). MERLO: A new tool and a new challenge in mathematics teaching and learning. In K. Beswick, T. Muir, \& J. Wells (Eds.), Proceedings of the 39th conference of the International Group for the Psychology of mathematics education (Vol. 2, pp. 57-64). Hobart: PME.

Carante, P. (2017). MERLO items as educational tools for mathematics teachers' professional development. Unpublished doctoral dissertation. Turin: University of Turin.

Carlile, P. (2002). A pragmatic view of knowledge and boundaries: Boundary objects in new product development. Organization Science, 13(4), 442-455.

Carlile, P. (2004). Integrative framework for managing knowledge across boundaries. Organization Science, 15(5), 555-568.

Cobb, P., Confrey, J., diSessa, A., Lehrer, R., \& Schauble, L. (2003). Design experiments in educational research. Educational Researcher, 32(1), 9-13.

Duval, R. (2006). A cognitive analysis of problems of comprehension in a learning of mathematics. Educational Studies in Mathematics, 61(1-2), 103-131.

Etkind, M., \& Shafrir, U. (2013). Teaching and learning in the digital age with pedagogy for conceptual thinking and peer cooperation. In L. Gómez Chova, A. López Martínez, \& I. Candel Torres (Eds.), 
Proceedings of the INTED-2013 conference (pp. 5342-5352). Valencia: International Association of Technology, Education and Development.

Etkind, M., Kenett, R. \&Shafrir, U. (2010). The evidence-based management of learning: Diagnosis and development of conceptual thinking with meaning equivalence reusable learning objects (MERLO). In C. Reading (Ed.), Proceedings of the 8th International Conference on Teaching Statistics (ICOTS-8). Ljubljana, Slovenia: ICOTS. (https://icots.info/icots/8/cd/pdfs/invited/ICOTS8_1C3_ETKIND.pdf).

Etkind, M., Kenett, R., \& Shafrir, U. (2016). Learning in the digital age with meaning equivalence reusable learning objects (MERLO). In E. Railean, G. Walker, A. Elçi, \& L. Jackson (Eds.), Handbook of research on applied learning theory and design in modern education (pp. 310-333). Hershey: IGI Global.

Fischbein, E. (1987). Intuition in science and mathematics: An educational approach. Dordrecht: D. Reidel.

Goos, M., \& Benisson, A. (2017). Boundary crossing and brokering between discipline in pre-service mathematics teacher education. Mathematics Education Research Journal, 30(3), 255-275.

Hegedus, S., \& Moreno-Armella, L. (2009). Intersecting representation andcommunication infrastructures. ZDM: The International Journal on MathematicsEducation, 41(4), 399-412.

Hoyles, C., Bakker, A., Kent, P., \& Noss, R. (2007). Attributing meanings to representations of data: The case of statistical process control. Mathematical Thinking and Learning, 9(4), 331-360.

Kilpatrick, J., Hoyles, C., Skovsmose \& Valero, P. (2005). Meanings of meaning of mathematics. In J. Kilpatrick, C., Hoyles\&O. Skovsmose(Eds), Meaning in mathematics education(pp. 9-16). New York, NY:Springer.

Kynigos, C., \& Kalogeria, E. (2012). Boundary crossing through in-service on-line mathematics teacher education: The case of scenarios and half-baked microworlds. ZDM: The International Journal on MathematicsEducation, 44(6), 733-745.

Mariotti, M. (2013). Introducing students to geometric theorems: How the teacher can exploit the semiotic potential of a DGS. ZDM: The International Journal on MathematicsEducation, 45(3), 441-452.

Mellone, M., Ramploud, A., Di Paola, B., \& Martignone, F. (2019). Cultural transposition: Italian didactic experiences inspired by Chinese and Russian perspectives on whole number arithmetic. ZDM: Mathematics Education, 51(1), 199-212.

Monod-Ansaldi, R., Aldon, G., \& Vincent, C. (2019). Objetsfrontières et brokering dans les négociationsen recherche orientée par la conception. Education \& Didactique, 13(2), 61-84.

Nizet, I., Monod-Ansaldi, R., Aldon, G., Prieur, M. \&Criquet, A. (2019). L'analyse de valuations dansunedémarche collaborative de recherche. La Revue l'Evaluationen Education, 1. (https://revue.leee. on-line/index.php/info/article/view/47).

Prodromou, T., Robutti, O., \& Panero, M. (2018). Making sense out of the emerging complexity inherent in professional development. Mathematics Education Research Journal, 30(4), 445-473.

Rasmussen, C., Zandieh, M. \&Wawro, M. (2009). How do you know which way the arrows go? The emergence and brokering of a classroom mathematics practice. In W.-M. Roth (Ed.), Mathematical representation at the interface of body and culture (pp. 171-218). Charlotte, NC:Information age publishing.

Robutti, O., Aldon, G., Cusi, A., Olsher, S., Panero, M., Cooper, J., Carante, P., \& Prodromou, T. (2019). Boundary objects in mathematics education and their role across communities of teachers and researchers in interaction. In G. Lloyd \& O. Chapman (Eds.), International handbook of mathematics teacher education (Vol. 3, pp. 211-240). Rotterdam: SensePublishers.

Robutti, O., Arzarello, F., Carante, P., Kenett, R., Prodromou, T., \& Shafrir, U. (2016). Meaning equivalence: A methodological tool for assessing deep understanding. In L. Gómez Chova, A. López Martínez, \& I. Candel Torres (Eds.), Proceedings of the INTED-2016 conference (pp. 7358-7367). Valencia: International Association of Technology, Education and Development.

Robutti, O., Carante, P., Prodromou, T., \& Kenett, R. (2020). Teachers involved in designing MERLO items. In M. Etkind \& U. Shafrir (Eds.), Pedagogy for conceptual thinking and meaning equivalence (pp. 6185). Hershey: IGI Global.

Schoenfeld, A. (2006). Design experiments. In J. Green, G. Camilli, \& P. Elmore (Eds.), Handbook of complementary methods in educationresearch (pp. 193-206). Mahwah: Lawrence Erlbaum Associates.

Shafrir, U., \& Kenett, R. (2015). Concept science evidence-based MERLO learning analytics. In E. Railean, G. Walker, A. Elçi, \& L. Jackson (Eds.), Handbook of research on applied learning theory and design in modern education (pp. 334-357). Hershey: IGI Global.

Sinclair, N., \& Robutti, O. (2012). Technology and the role of proof: The case of dynamic geometry. In M. Clements, A. Bishop, C. Keitel-Kreidt, J. Kilpatrick, \& F. Leung (Eds.), Third international handbook of mathematics education (pp. 571-596). New York: Springer.

Sinclair, N., \& Yerushalmy, M. (2016). Digital technology in mathematics teaching and learning: A decade focused on theorising and teaching. In Á. Gutiérrez, G. Leder, \& P. Boero (Eds.), The second handbook of 
research on the psychology of mathematics education: The journey continues (pp. 235-274). Rotterdam: Sense Publishers.

Star, S. (2010). This is not a boundary object: Reflections on the origin of a concept. Science, Technology, \& Human Values, 35(5), 601-617.

Star, S., \& Griesemer, J. (1989). Institutional ecology, 'translations' and boundary objects: Amateurs and professionals in Berkeley's Museum of Vertebrate Zoology, 1907-39. Social Studies of Science, 19(3), $387-420$.

Sullivan, P., \& Davidson, A. (2014). The role of challenging mathematical tasks in creating opportunities for student reasoning. In J. Anderson, M. Cavanagh, \& A. Prescott (Eds.), Proceedings of the $37^{\text {th }}$ annual conference of the mathematics education research Group of Australasia (pp. 605-612). Sydney: MERGA.

Thibault, M., \& Sinclair, N. (2019). Conception de tâches MERLO: Un dispositifdans la formation continue pour l'enseignement de la géométrie. Canadian Journal of Science, Mathematics and Technology Education, 19(2), 189-203.

Trompette, P., \& Vinck, D. (2009). Revisiting the notion of boundary object. Revue d'anthropologie des connaissances, 3(1), 3-25.

Wenger, E. (1998). Communities of practice: Learning, meaning, and identity. Cambridge: Cambridge University Press.

Wenger, E. (2010). Conceptual tools for CoPs as social learning systems: Boundaries, identity, trajectories and participation. In C. Blackmore (Ed.), Social learning systems and communities of practice (pp. 125-143). London, UK:Springer.

Wenger, E., McDermott, R., \& Snyder, W. (2002). Cultivating communities of practice: A guide to managing knowledge. Cambridge: Harvard Business School Press.

Yackel, E., \& Cobb, P. (1996). Sociomathematical norms, argumentation, and autonomy in mathematics. Journal for Research in Mathematics Education, 27(4), 458-477.

Publisher's Note Springer Nature remains neutral with regard to jurisdictional claims in published maps and institutional affiliations. 